\title{
Differential ferrioxamine test for measuring chelatable body iron
}

\author{
J. FIELDING \\ From Paddington General Hospital, London
}

SYNOPSIS The differential ferrioxamine test is a simple method for the measurement of chelation? of body iron by desferrioxamine. A single six-hour specimen of urine is obtained after intravenous $\vec{\Delta}_{\infty 0}$ Desferal, accompanied by ${ }^{59} \mathrm{Fe}$-ferrioxamine. Two values are measured: $F_{d}$, the excretion of ferrioxamine derived from body iron by chelation, and $F_{e x}$, the proportion of ferrioxamine excreted ${ }_{\infty}^{\infty}$ from a known intravenous dose. The data enables $F_{v}$, chelation of iron in vivo, to be calculated by 9 simple proportion. Desferrioxamine chelation proceeds for about half an hour after injection.

The results in normal subjects, in cases with known high iron stores, and in cases of iron-deficiencye anaemia are described. High, normal, and low body iron states have been differentiated. $F_{v}$ values in the higher ranges obtained in iron-storage diseases and in haemolytic states are differentiated $\mathbb{K}^{\circ}$ by the pattern of excretion, high $F_{d}$ values and low $F_{\text {ex }}$ values respectively.

It is suggested that there are two main sources of chelatable body iron: as ferritin-haemosiderinor and as iron newly released from haem in a more readily chelatable form. The significance of variableo chelation susceptibility in iron metabolism is briefly discussed. It is suggested that variable chelat $-\stackrel{-}{\xi}$ ability of different sources of body iron may explain the preferential utilization of iron released from red cells or absorbed from the intestine, rather than storage iron, in the biosynthesis of haem

The clinical assessment of the state of the body iron is made by indirect methods, which include haemoglobin concentration, mean corpuscular haemoglobin concentration, examination of the stained blood film, serum iron concentration, and the amount of iron-binding globulin, transferrin. There is a considerable literature dealing with the interrelationships of these parameters and their interpretation (see, for instance, Beutler, Fairbanks, and Fahey, 1963; Harris, 1963). In some situations the interpretation of these investigations taken together is unmistakable: in severe iron deficiency, for instance, a characteristic pattern of results is obtained. Nevertheless, these measurements are subject to many influences such as infection, neoplasm, renal failure, and metabolic disorders, which affect their values apart from iron status, and in such conditions interpretation may be speculative. Furthermore, they are of minor importance in the diagnosis of iron storage diseases.

A more direct approach to assessing storage iron may be by needle biopsy of the marrow, staining the aspirated material for ferritin and haemosiderin by the prussian blue reaction (Rath and Finch, 1948). Received for publication 28 September 1964.
As a guide to iron deficiency, marrow puncture is, especially useful, although the concentration of ferritin must attain certain minimal levels before it becomes visible by this staining method (Shoderf and Sturgeon, 1960). The rare but classic case of atransferrinaemia (Heilmeyer, Keller, Vivell, Keider? ling, Betke, Wöhler, and Schultze, 1961) showed that marrow iron does not necessarily reflect tota $\bar{R}$ iron stores: the marrow was entirely devoid of non 옥 haem iron and the liver and spleen were overloaded with iron. In pulmonary and in renal haemosiderosis. marrow iron may be entirely absent; in haemoñ chromatosis there is a proportionally smaller increase in iron in the marrow than in the liver and the pancreas; in haemosiderosis the marrow receives a relatively greater proportion of the iron overload than in haemochromatosis. Prussian-blue-reactins iron may often be irregularly distributed in marrow a finding which may be appreciated when the aspirated material contains many cellular marrowo granules. There is room, therefore, for some doub when the aspirated specimen contains only a feus small granules.

Liver puncture is an important method of assessing iron storage disease and their differential diagnosis 
(Williams, Scheuer, and Sherlock, 1962), but does not commend itself to wide application in the study of iron stores. Moreover, there are few data on the correlation between chemical assay of liver iron and histochemical appearances.

Body iron stores have also been measured by experimental methods. Hynes (1949) removed a small volume of blood each day for many months until the onset of iron-deficiency anaemia; larger amounts of blood have been withdrawn by venesecttion until the subject fails to make a spontaneous recovery to the induced anaemia (Haskins, Stevens, Finch, and Finch, 1952). Radio-isotope dilution techniques have also been used: these require some weeks of observation and give results lower than after phlebotomy since much of the storage iron fails to exchange with the isotope (Finch, 1959). Chelating agents with strong iron affinity have been used: Korman (1960) used ${ }^{59} \mathrm{Fe}-\mathrm{EDDHA}$ as an isotope dilution technique and claimed to distinguish iron deficiency, renal anaemia, and the anaemia of infection. Post-mortem assays of non-haem iron have also been made (Morgan and Waters, 1963).

Desferrioxamine B (Desferal, Ciba) is a powerful and specific chelator of trivalent iron, forming the ferric chelate, ferrioxamine B (Fig. 1). Chelation

$\begin{array}{cccc}\circ \mathrm{OH} & \circ & \mathrm{OH} & O \mathrm{OH} \\ \mathrm{CH}_{2} \mathrm{C}-\mathrm{NH}\left(\mathrm{CH}_{2}\right)_{5} \mathrm{NHCO}\left(\mathrm{CH}_{2}\right)_{2} \mathrm{C}-\mathrm{N}\left(\mathrm{CH}_{2}\right)_{3} \mathrm{NHCO}\left(\mathrm{CH}_{3}\right)_{2} \mathrm{C}-\mathrm{N}\left(\mathrm{CH}_{3}\right)_{5} \mathrm{NH}_{2}+\mathrm{Fe}^{+3}\end{array}$ Desferrioxamine

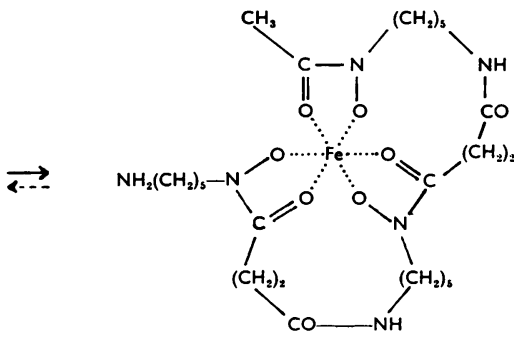

$+3 \mathrm{H}^{+}$

Ferrioxamine

FIG. 1. The chelation of iron by desferrioxamine.

occurs in vivo and ferrioxamine is excreted in the urine. The highly specific affinity for iron has suggested the use of desferrioxamine to increase iron excretion in haemochromatosis, in other forms of siderosis, and to bind iron in the treatment of acute poisoning (Moeschlin, 1962). A further use for desferrioxamine has been suggested (Keberle, 1964), as a screening test for iron-storage disease by measuring the increase in urinary iron after an intramuscular injection of the chelator.

The source of iron chelated by desferrioxamine is exclusively non-haem iron (Wöhler, 1962) but the sites of chelation are not yet fully determined. Iror stores in the form of ferritin are certainly an important source but there is doubt about haemosiderin (Mann and Meier, 1962). Some degree of iron capture from transferrin has been demonstrated in vitro (Wöhler, 1962): in vivo it appears that this does not occur to any measurable degree (Hallberg, 1964; Ventura, 1964).

The method described here is based on chelation of body iron by desferrioxamine. Urinary iron is measured as ferrioxamine, and the proportion of ferrioxamine excreted in the urine is measured isotopically. Thus the amount of chelation in vivo may be calculated. The method is applicable to conditions of both high and low iron stores. The object of the present paper is primarily to describe the method but it will also be shown that a readily chelatable form of iron occurs in haemolytic anaemias.

\section{PRELIMINARY INVESTIGATION OF THE URINARY EXCRETION OF FERRIOXAMINE}

It has been reported (Wöhler, 1962) that all ferrioxamine given by intramuscular or intravenous injection appears in the urine. If this were so, urinary ferrioxamine (or urinary iron) could be used as a measure of body iron chelation by desferrioxamine. However, utilization of ferrioxamine iron for haemoglobin synthesis has also been reported (Bannerman, Callender, and Williams, 1962) which implies retention of a proportion of the ferrioxamine and so invalidates urinary iron as a direct measure of chelation. The point was therefore reinvestigated.

After an intravenous injection of ferrioxamine the proportion excreted in the urine of normal subjects is in the range of about 50 to $70 \%$ of the dose in 72 hours (Fig. 2). In haematological disorders this

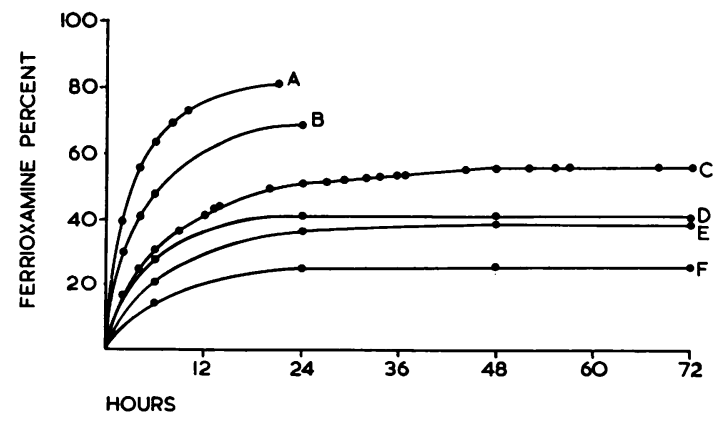

FIG. 2. Urinary excretion after $50 \mathrm{mg} . / \mathrm{kg}$. ferrioxamine intravenously. $A$, haemochromatosis; $B$, treated iron deficiency; $C$ and $D$, normal; $E$ and $F$, iron deficiency. 


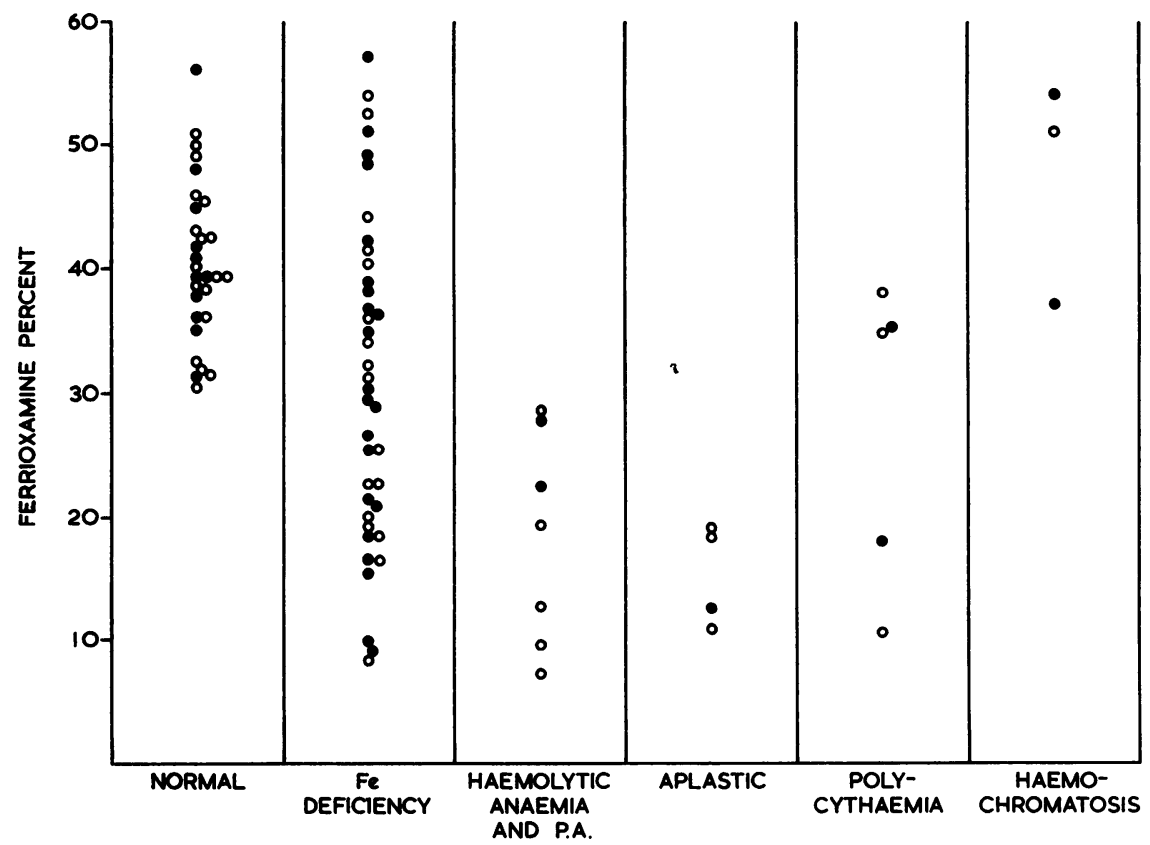

FIG. 3. Six-hour urinary excretion after $50 \mathrm{mg} . / 60 \mathrm{~kg}$. ferrioxamine intravenously. Solid dots $=$ chemical assay. Open circles $=$ isotope assay of ${ }^{59} \mathrm{Fe}$-ferrioxamine.

may vary from as little as $10 \%$ to as much as $100 \%$; in varying degree ferrioxamine is retained and diverted to other metabolic pathways. This variation is not due to delayed excretion, since little if any is excreted after 72 hours. It was confirmed that a proportion of ferrioxamine iron appears later as circulating haemoglobin.

The excretion of ferrioxamine in six hours is a consistent fraction of total excretion. Figure 3 shows six-hour ferrioxamine excretion following an intravenous dose. In normal subjects about 30 to $50 \%$ of the dose is excreted in six hours; in iron-deficiency anaemias about half the cases excrete a lesser proportion of ferrioxamine than normal subjects; in haemolytic anaemia and untreated pernicious anaemia excretion is invariably low; it is low also in aplastic anaemia, in leukaemia, and in some polycythaemias. In three cases of haemochromatosis the proportion of the dose excreted was in the normal range. In a case of erythrogenesis imperfecta, with transfusional haemosiderosis, $90 \%$ of the dose was excreted in six hours. Ferrioxamine excretion thus varies widely from case to case; it varies also at different stages of disease in the same subject.

It follows from these observations that when desferrioxamine chelates body iron to form ferrioxamine, the amount of ferrioxamine (or of iron) appearing in the urine is not a direct measure of the amount formed in vivo. If it is desired to use urinary ferrioxamine as an indication of the amount formect in vivo, the proportion of ferrioxamine which doesi not appear in the urine must be known for eacho individual patient at the time of the test.

\section{URINARY EXCRETION OF ${ }^{59}$ FE-FERRIOXAMINE}

When a standard body weight dose of ferrioxamine labelled with ${ }^{59} \mathrm{Fe}$-ferrioxamine is injected intra용 venously, the proportion of isotope excreted in the urine is the same as the proportion of chemically. estimated ferrioxamine (Fielding, 1964). This is sof whether body iron stores are high, as in haemo 3 chromatosis, or absent, as in iron-deficient subjects? It follows that no exchange takes place between iron as ferrioxamine and other body iron. The excretion? of the isotope may therefore be used to monitor the excretion of injected ferrioxamine.

\section{THE DIFFERENTIAL FERRIOXAMINE TEST}

PRINCIPLE An intravenous injection is given consisting of two components: (1) a dose of desferrioxamine calculated according to body weight, and (2) a dose of ferrioxamine labelled with approximately $2 \mu \mathrm{C} \mathrm{Fe}^{59}$ also calculated according to body weight. The urinary excretion of injected ferrioxamine is measured by isotope assay. Total ferrioxamine excretion is assayed chemically this is derived from injected ferrioxamine plus that formed from body iron by desferrioxamine. The difference therefore, measures excretion derived from chelation 
alone, and the amount chelated in vivo is calculated by simple proportion from the isotope excretion data.

THE TEST DOSE Desferrioxamine methanesulphonate (Desferal, Ciba), $500 \mathrm{mg}$., is dissolved in exactly $4.8 \mathrm{ml}$. sterile distilled water and to this is added approximately $2 \mu \mathrm{C} \mathrm{Fe} e^{59}$ in $0.2 \mathrm{ml}$. as ferric chloride. Chelation of labelled iron is completed within one minute, resulting in the formation of approximately $5 \mu \mathrm{g}$. ${ }^{59} \mathrm{Fe}$-ferrioxamine, depending on the specific activity of the isotope used. To this, $50 \mathrm{mg}$. ferrioxamine hydrochloride (Ciba), dissolved in exactly $1 \mathrm{ml}$. sterile distilled water, is added. The total volume is now $6 \mathrm{ml}$. and this is the standard dose used for a subject weighing $60 \mathrm{~kg}$. The dose is adjusted for body weight to the nearest $0.5 \mathrm{ml} ;$. e.g., a subject of body weight $52 \mathrm{~kg}$. is given $5 \mathrm{ml}$. Sufficient solution is made to provide a standard for $\mathrm{Fe}^{59}$ assay, and for chemical estimation of ferrioxamine should this be desired.

PREPARATION OF PATIENT The tests described here were all begun between 9.30 and 11 a.m. It is essential that no iron therapy of any kind should be given during the previous seven days. Before the injection, the bladder is emptied. Normal fluid intake is permitted since the results are unaffected by a wide range of urinary volumes. It is desirable to keep the six-hour urinary volume to less than $600 \mathrm{ml}$. Ward patients, who often have high urinary outputs on free fluids, should be restricted if necessary to normal intakes.

INJECTION TECHNIQUE A two-syringe technique will be found convenient, using the first to ensure clean venepuncture and to collect a blood specimen if needed, and a second syringe to give the intravenous dose. The injection is given slowly: the face may flush with rapid injection. Almost all subjects tolerate $0.5 \mathrm{ml}$. in 10 seconds and none experience discomfort with $0.5 \mathrm{ml}$. in 15 seconds. The exact volume injected is obtained by weighing an equal volume of water expelled from the same syringe and needle, and the exact dose of ferrioxamine injected is calculated.

URINE COLLECTION Most results reported here are based on two-hourly collections of urine for a total of six hours. For the purpose of the test, only a single six-hour collection of urine is required. The volume of urine is recorded and two estimations are made:

$1 \mathrm{Fe}^{59}$ isotope content This measures the proportion of injected ferrioxamine excreted in the urine and is expressed in $\mathrm{mg}$. ferrioxamine $\left(\mathrm{F}_{\mathrm{ex}}\right)$.

2 Total ferrioxamine The total ferrioxamine content $\left(F_{t}\right)$ is estimated chemically by the method of Fielding and Brunström (1964). This measures ferrioxamine excretion derived from injection plus chelation of body iron by desferrioxamine. The difference, $F_{t}$ minus $F_{e x}$, is therefore ferrioxamine derived from chelation alone $\left(F_{d}\right)$.

It will be shown below that $F_{v}$, the amount of ferrioxamine formed in vivo, is given by the expression $\frac{F \times F_{d}}{F_{e x}}$ mg., where F mg. is the dose of ferrioxamine injected. It is expressed as $\mu \mathrm{g} . / \mathrm{kg}$. body weight.
RESULTS

Figure 4 shows the pattern of results obtained in a normal subject. $F_{t}$ is the amount of ferrioxamine excretion estimated chemically and derives from both ferrioxamine injected and from chelation in vivo. $\mathrm{F}_{\mathrm{ex}}$, estimated isotopically, is the ferrioxamine excretion derived from the intravenous dose of ferrioxamine. The difference, $F_{d}$, is the ferrioxamine excretion derived from chelation in vivo.

Figure 5 shows the variable pattern of results obtained in a normal subject, in an iron-deficient subject, in a case of pernicious anaemia, and in a case of aplastic anaemia; in Fig. 6, on a smaller ordinate scale, the results in a case of untreated haemochromatosis, in a normal subject, and in a further case of severe iron-deficiency anaemia. These cases illustrate the variability found in both absolute and relative amounts of ferrioxamine formed in vivo and the proportion excreted in the urine.

EXCRETION OF CHELATED AND OF INJECTED FERRIOXAMINE In order to deduce the amount of chelation in vivo from the excretion of injected ferrioxamine, it must be shown that both sources of ferrioxamine follow similar metabolic pathways.

Figure 7 shows that there is a linear relationship between the excretion of the two sources of ferrioxamine from the first observation at two hours, up to periods of 21 hours, in varying clinical states. Once chelation has reached its maximum, urinary excretion of the two sources of ferrioxamine follow each other closely and it is therefore reasonable to assume their metabolic behaviour is identical. Extrapolation of the graphs is not through the origin, since some time delay must occur in the formation of $F_{d}$ by chelation. It is clear, however, that chelaton is maximal in less than two hours.

CHELATION TIME The chelator, desferrioxamine, is partly excreted in the urine and partly destroyed enzymatically in the plasma (Peters, 1964). Thus time for active chelation with body iron is limited. It is likely that reaction time is small and that most chelation takes place rapidly after injection (Schubert 1964). Analysis of the time relationships of $F_{d}$ and $F_{\text {ex }}$ suggests that chelation continues for about half an hour after injection.

Ferrioxamine excretion between two and 10 hours after injection approximates to a linear function of $\log$ time. Figure 8 shows $F_{d}$ (chelated) and $F_{\text {ex }}$ (injected) ferrioxamine excretion plotted against log time in a case of haemochromatosis, in a normal subject, and in a case of pernicious anaemia. Extrapolation of the graphs to their zero intercepts gives the difference in time between zero $F_{e x}$, which 


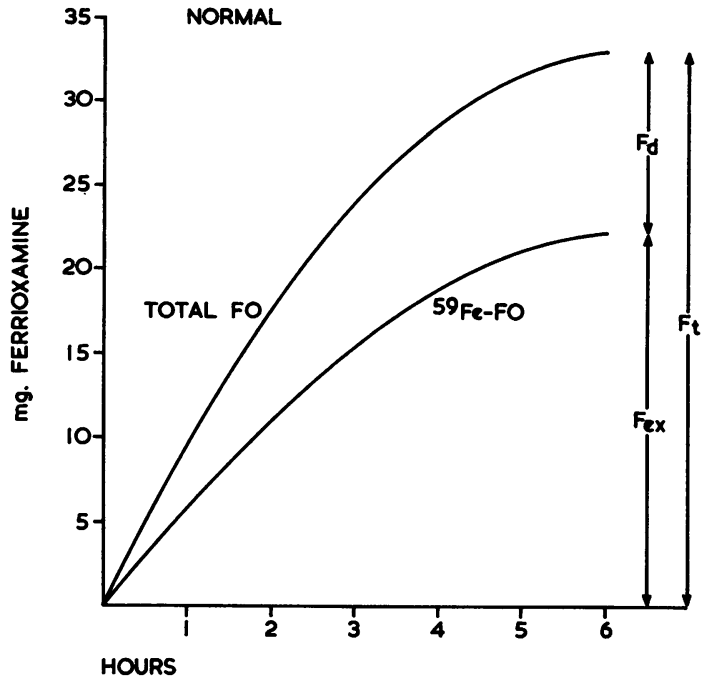

FIG. 4. Differential ferrioxamine test in a normal subject. $\mathrm{F}_{\mathrm{t}}=$ total ferrioxamine in urine; $\mathrm{F}_{\mathrm{ex}}=$ ferrioxamine excretion by ${ }^{59}-\mathrm{Fe}$ assay. $\mathrm{F}_{\mathrm{d}}=\mathrm{F}_{\mathrm{t}}-\mathrm{F}_{\mathrm{ex}}=$ urinary ferrioxamine from chelation in vivo.
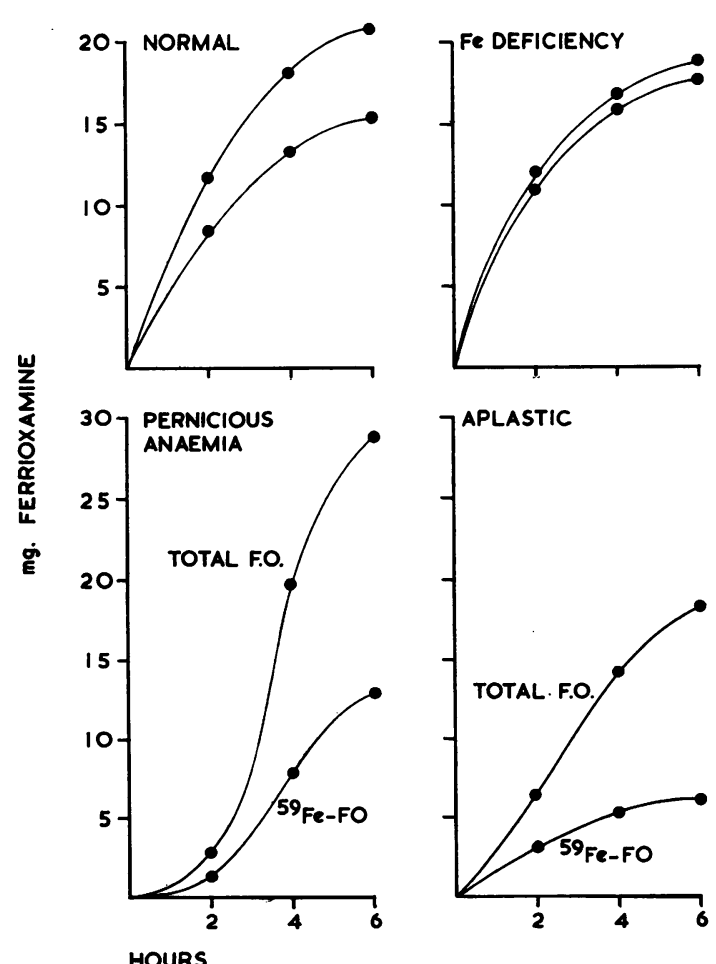

FIG. 5. Differential ferrioxamine test in a normal subject and in iron deficiency, pernicious anaemia, and aplastic anaemia.

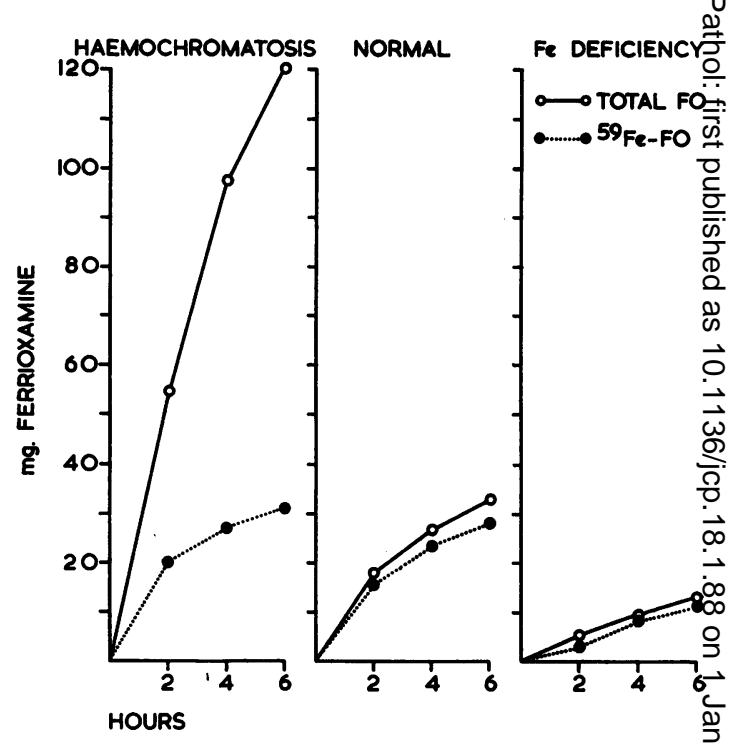

FIG. 6. Differential ferrioxamine test in haemochroma tosis, in a normal subject, and in severe iron deficiency.

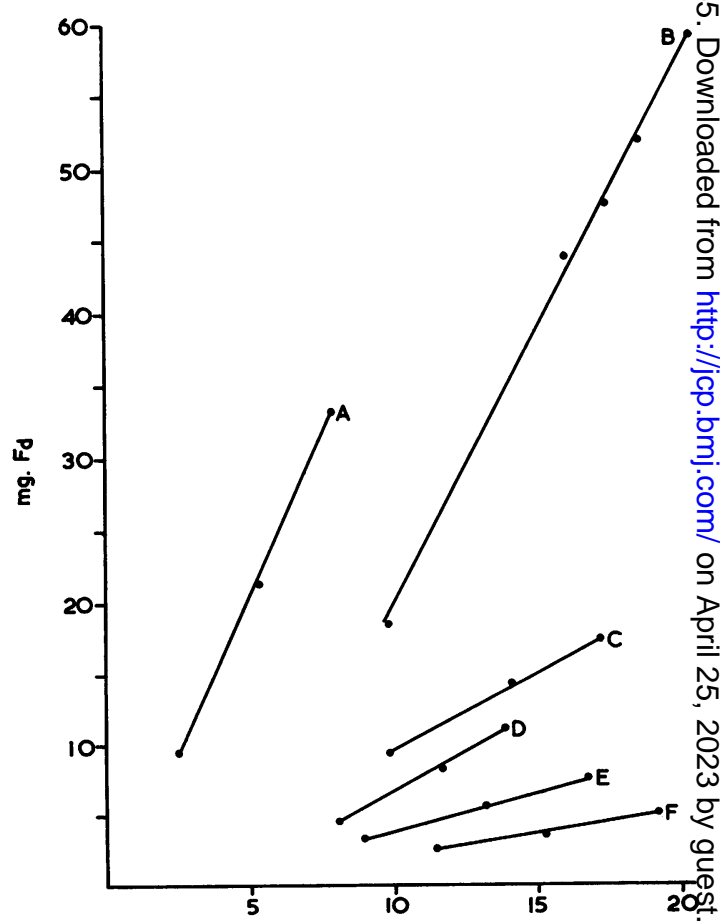

mg. $F_{\text {ex }}$

FIG. 7. The relationship between urinary excretion injected ferrioxamine $\left(\mathrm{F}_{\mathrm{ex}}\right)$ and ferrioxamine chelated vivo $\left(\mathrm{F}_{\mathrm{d}}\right)$. The lowest point on each graph is a two-hout reading. 

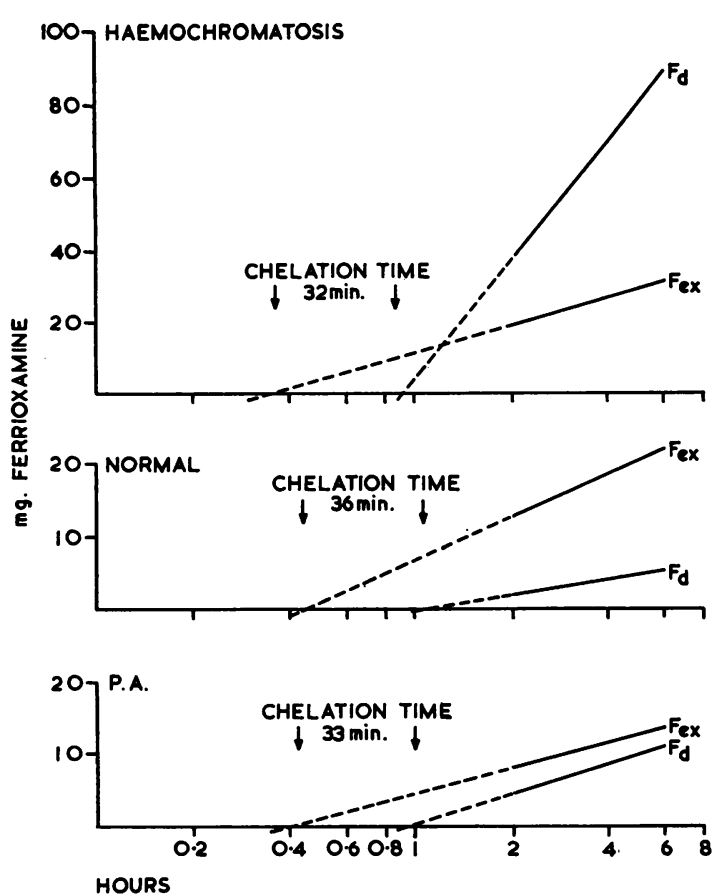

FIG. 8. $\quad \mathrm{F}_{\mathrm{d}}$ and $\mathrm{F}_{\mathrm{ex}}$ plotted against log time. The difference in zero intercepts indicates the time during which chelation is active (see text).

occurs first, since it is injected, and zero $F_{d}$ which is delayed, since it is formed by chelation. The difference in the zero intercepts indicates the time difference between injection and chelate formation, on the theoretical assumption that all chelation takes place at a given moment some time after injection. In all three conditions chelation time appears to be about half an hour. A similar order of time has been found in other conditions analysed in this way: it seems evident that the time of formation of ferriox- amine is small compared with the period of observation in the test.

DEDUCTION OF CHELATION IN VIVo Since the excretion of injected $\left(\mathrm{F}_{\mathrm{ex}}\right)$ and chelated in vivo $\left(\mathrm{F}_{\mathrm{d}}\right)$ ferrioxamine share a linear relationship, and since the time of formation of $F_{d}$ is small compared with the period of observation, the following simple proportion applies:

If $F_{e x} m g$. is excreted from a dose of $F$ mg., then $F_{d}$ mg. is excreted from $\frac{F \times F_{d}}{F_{e x}}$ mg. ferrioxamine. This value, $F_{v}$, is therefore the amount of ferrioxamine formed in vivo and is expressed in micrograms per kilogram body weight.

In order to validate and interpret results, the test has been applied to conditions of known iron status.

Fv IN HIGH IRON STORAGE STATES Figure 9 shows the results in conditions with expected iron stores above normal. In the first column are normal subjects, with $F_{v}$ range of 110 to $420 \mu \mathrm{g} . / \mathrm{kg}$.: in the second column there is a group of five subjects of normal iron status who were given a minor overload of $700 \mathrm{mg}$. of iron by intramuscular injection eight months before the test: they now show chelation in vivo in the high normal to a little above normal range. In the third column are results in clinical conditions with expected increased iron stores. The highest findings, of the order of $4,000 \mu \mathrm{g} . / \mathrm{kg}$., were found in a case of aplastic anaemia with marked haemolytic activity, and in a case of leukaemia also showing active haemolysis. Cases of hypoplastic anaemia, pernicious anaemia, other haemolytic anaemias, myelosclerosis, and sideroblastic anaemia have given values above the normal range. Two cases of untreated haemochromatosis gave results of $2,150 \mu \mathrm{g} . / \mathrm{kg}$. and $2,090 \mu \mathrm{g} . / \mathrm{kg}$. respectively. In a case of haemosiderosis (erythrogenesis imperfecta transfused for 16 years), $F_{v}$ was $1,950 \mu \mathrm{g} . / \mathrm{kg}$. A third case of haemochromatosis treated by vene-

TABLE I

Fv IN THREE CASES OF PERNICIOUS ANAEMIA BEFORE AND DURING VITAMIN $B_{12}$ THERAPY

\begin{tabular}{|c|c|c|c|c|c|c|c|}
\hline $\begin{array}{l}\text { Case, Sex, } \\
\text { Age }\end{array}$ & & & $H b(g . \%)$ & P.C.V. $(\%)$ & $\begin{array}{l}\text { Serum Fe } \\
(\mu g . \%)\end{array}$ & $\begin{array}{l}U I B C \\
(\mu g . \%)\end{array}$ & $\begin{array}{l}F_{v}(\mu g . / k g . \\
\text { normal, 110-418) }\end{array}$ \\
\hline $\begin{array}{l}\text { N.B. } \\
\text { F } \\
78\end{array}$ & Before $\mathbf{B}_{12}$ & $\begin{array}{l}+7 \text { days } \\
+28 \text { days } \\
+46 \text { days }\end{array}$ & $\begin{array}{r}6 \cdot 6 \\
8 \cdot 1 \\
11 \cdot 7 \\
11 \cdot 4\end{array}$ & $\begin{array}{l}20 \\
41 \\
40\end{array}$ & $\begin{array}{r}120 \\
46 \\
70 \\
-\end{array}$ & $\begin{array}{r}90 \\
239 \\
230 \\
-\end{array}$ & $\begin{array}{r}972 \\
578 \\
320 \\
46\end{array}$ \\
\hline $\begin{array}{l}\text { M.L. } \\
\text { F } \\
88\end{array}$ & Before $\mathbf{B}_{12}$ & $\begin{array}{l}+7 \text { days } \\
+34 \text { days }\end{array}$ & $\begin{array}{r}8 \cdot 1 \\
8 \cdot 7 \\
10 \cdot 5\end{array}$ & $\begin{array}{l}25 \\
28 \\
36\end{array}$ & $\begin{array}{r}166 \\
56 \\
35\end{array}$ & $\begin{array}{l}125 \\
229 \\
193\end{array}$ & $\begin{array}{r}1,536 \\
838 \\
692\end{array}$ \\
\hline $\begin{array}{l}\text { C.M. } \\
\text { F } \\
92\end{array}$ & Before $\mathbf{B}_{12}$ & +7 days & $\begin{array}{r}9 \cdot 3 \\
10 \cdot 5\end{array}$ & $\begin{array}{l}38 \\
38\end{array}$ & $\begin{array}{r}141 \\
60\end{array}$ & $\begin{array}{r}51 \\
225\end{array}$ & $\begin{array}{r}1,032 \\
785\end{array}$ \\
\hline
\end{tabular}


TABLE II

\begin{tabular}{|c|c|c|c|c|c|c|}
\hline $\begin{array}{l}\text { Case, Sex, } \\
\text { Age }\end{array}$ & Fv IN TWO CASES OF & $\begin{array}{c}\text { POLYCYTHAEMIA } \\
\qquad b(g . \%)\end{array}$ & $\begin{array}{c}\text { VERA BEFORE } \\
\text { P.C.V. }(\%)\end{array}$ & $\begin{array}{l}\text { AND AFTER } \\
\text { Serum Fe } \\
(\mu g . \%)\end{array}$ & $\begin{array}{c}\text { P }^{32} \text { THERAPY } \\
\text { UIBC } \\
(\mu g . \%)\end{array}$ & $F_{v}(\mu g . / k g)$. \\
\hline $\begin{array}{l}\text { T.W. } \\
\text { M } \\
\mathbf{5 3}\end{array}$ & $\begin{array}{l}\text { Before }^{32} \mathbf{P} \\
\text { After }{ }^{\mathbf{s 2}} \mathbf{P}\end{array}$ & $\begin{array}{l}18 \cdot 0 \\
13 \cdot 8\end{array}$ & $\begin{array}{l}60 \\
44\end{array}$ & $\begin{array}{r}78 \\
182\end{array}$ & $\overline{211}$ & $\begin{array}{l}203 \\
412\end{array}$ \\
\hline $\begin{array}{l}\text { M.T. } \\
\text { F } \\
71\end{array}$ & $\begin{array}{l}\text { Before }{ }^{32} \mathbf{P} \\
\text { After }{ }^{32} \mathbf{P}\end{array}$ & $\begin{array}{r}18 \cdot 0 \\
9 \cdot 6\end{array}$ & $\begin{array}{l}68 \\
32\end{array}$ & $\begin{array}{r}116 \\
91\end{array}$ & $\begin{array}{l}244 \\
191\end{array}$ & $\begin{array}{l}174 \\
506\end{array}$ \\
\hline
\end{tabular}

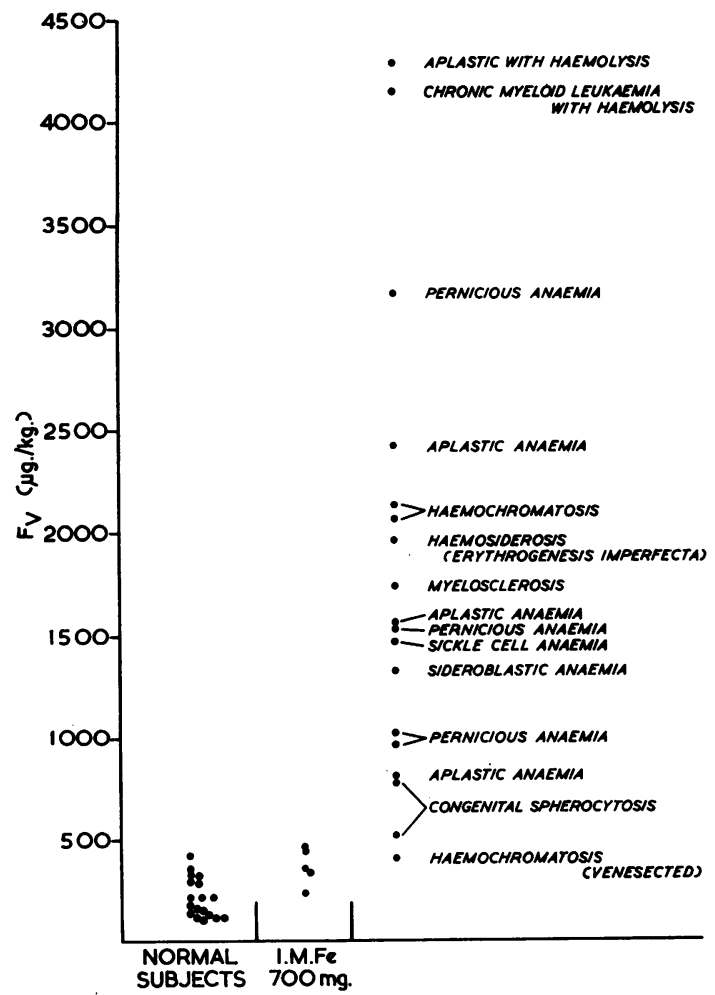

FIG. 9. In vivo chelated ferrioxamine $\left(\mathrm{F}_{\mathrm{v}}\right)$ in normals, in five subjects given an overload of $700 \mathrm{mg}$. intramuscular iron eight months before, and in high storage iron states.

section for two years gave an $F_{v}$ value of $460 \mu \mathrm{g}$. $/ \mathrm{kg}$. at a time when liver biopsy showed no stainable iron.

Inspection of these results suggests that there are at least two sources of iron with different chelation susceptibility: first, storage iron as ferritin and haemosiderin, increased in iron-storage disease or whenever haemoglobin falls without blood loss; second, a source of iron more readily chelated, associated with haemolytic states. The chemical state of this iron is unknown: in part it may be newly deposited ferritin, but the evidence suggests the possibility of at least one other form of iron soon after its release from haem.
Fv DURING REDISTRIBUTION OF BODY IRON In some clinical situations body iron is redistributed from on compartment to another, without a change of total body iron. Three cases of pernicious anaemia before and during vitamin $B_{12}$ therapy are shown in Table I. As haemoglobin rises and iron stores move from non-haem to haem, there is a progressive faff in chelatable iron. In one case (N.B.) chelation was followed into the iron-deficient range at which poin $\vec{t}$ no further rise in haemoglobin occurred until iro@ was given therapeutically.

It may be seen that the largest fall in chelatio takes place within a few days of therapy, befor haemoglobin has greatly increased. It may b\& recalled that the first result of vitamin $B_{12}$ therapy is cessation of ineffective erythropoiesis, that is, the breakdown of erythrons before release into the circulation. This result supports the view that iro released from haem by haemolysis or ineffective erythropoiesis is specially susceptible to chelation. $\complement$

The opposite situation is seen in two cases of poly $\overrightarrow{\overrightarrow{6}}$ cythaemia vera treated with $\mathbf{P}^{32}$ (Table II). A erythropoiesis diminishes and haemoglobin falls iron is transferred from haemoglobin to storage compartments and this is reflected in rising $\mathrm{F}_{\bar{\Phi}}$ values. It may be observed in this situation that the increase in chelatable iron for a given fall in haemo 3 globin is far less than the fall in chelatable iron for similar or smaller increase in haemoglobin in pernicious anaemia soon after vitamin $B_{12}$ therapy This also supports the view of a readily chelatable form of iron other than ferritin, soon after
release from haem.

IRON-DEFICIENCY ANAEMIA Figure 10 shows thô results in established iron deficiency among patients with haemoglobin less than $10 \mathrm{~g} . \%$, with low seruno iron levels and serum transferrin saturation less thaf $15 \%$, all of whom subsequently responded to irow therapy. The range in normal subjects is shown if the left column. In 26 of 31 cases, $F_{v}$ was below the normal range. In five cases iron chelation was within the normal range. These findings are discussed below

\section{DISCUSSION}

The measurement of excretion of an iron chelate 


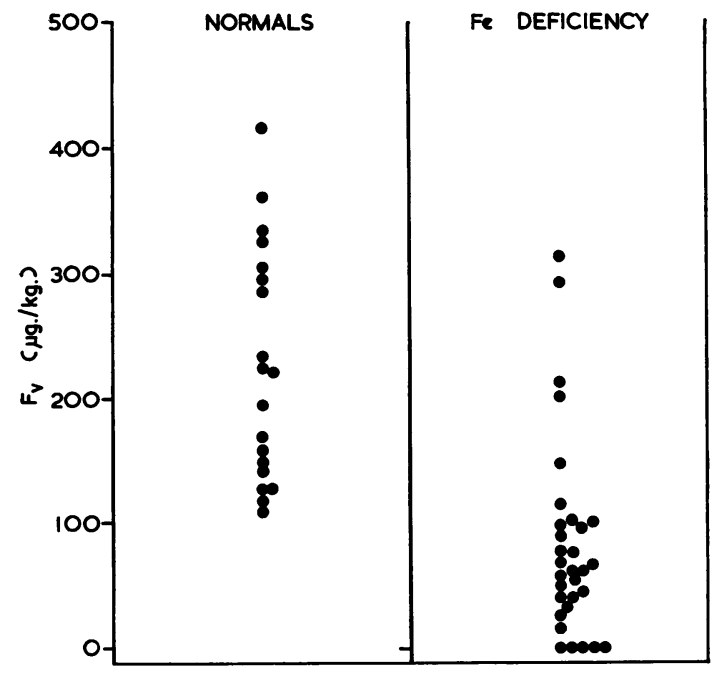

FIG. 10. Chelated ferrioxamine $\left(\mathrm{F}_{\mathrm{v}}\right)$ in vivo in normals and in untreated iron-deficiency anaemias.

after injection of a chelator to indicate iron store status contains two assumptions. First, that the amount of chelate formed in vivo is proportional to iron stores: this will be considered below. Second, that the amount of chelate excreted is a measure of the amount formed in vivo. In the case of ferrioxamine, the proportion of an intravenous dose which later appears in the urine varies widely from case to case and at different stages of the same disorder. Consequently urinary ferrioxamine excretion does not directly measure the amount of ferrioxamine formed from its chelator. Additional information is required to interpret the amount formed in terms of the amount excreted.

The method of obtaining this information in the test depends on three characteristics of desferrioxamine-ferrioxamine chelation.

1 The iron in ferrioxamine does not exchange with other body iron. When ferrioxamine is injected accompanied by a label of $\mathrm{Fe}^{59}$ ferrioxamine, the proportion of isotope excreted is the same as that of chemically determined ferrioxamine (if exchange took place the proportion of isotope would be lower). This has been demonstrated when iron stores are high as in haemochromatosis and in haemolytic anaemia, in normals, and in irondeficient subjects (Fielding, 1964). The excretion of isotope has therefore been used to monitor the excretion of injected ferrioxamine.

2 There is a linear relationship between the excretion of chelated in vivo $\left(\mathrm{F}_{\mathrm{d}}\right)$ and injected $\left(\mathrm{F}_{\mathrm{ex}}\right)$ ferrioxamine from the first observation at two hours up to periods of 21 hours. It may be assumed, therefore, that ferrioxamine chelated from body iron behaves metabolically in the same way as injected ferrioxamine; it also means that maximum chelation has been achieved in less than two hours.

3 Analysis of the time relationship of $F_{e x}$ and $F_{d}$ shows that active chelation does not usually continue for more than half an hour.

These characteristics permit chelation in vivo $\left(\mathrm{F}_{\mathrm{v}}\right)$ to be calculated by simple proportion: $F_{v}=\frac{F \times F_{d}}{F_{e x}}$ mg., and the result is expressed as micrograms per kilogram body weight. In this expression $F /$ weight is the dose of ferrioxamine given and is constant. Thus $F_{v}$ depends upon the ratio $F_{d} / F_{e x}$. This confers certain useful features on the method: $F_{d} / F_{e x}$ is a linear function and if chelation were instantaneous, the graph $F_{d} / F_{e x}$ would pass through the origin (Fig. 7) and there would be no zero intercept difference on the time base (Fig. 8); the ratio $F_{d} / F_{e x}$ would be entirely independent of time. In fact the ratio rises slightly between two and six hours and is for practical purposes constant thereafter. The timing of urine specimens is thus not critical above six hours, and the same result is obtained from a six- or a seven-hour specimen.

The ratio is independent of renal function, since both terms of the ratio are equally affected by variations in renal function. Gross renal insufficiency places a limitation on the test in that sufficient ferrioxamine must be excreted to make accurate chemical assay possible.

The ratio is independent of minor losses in urine collection, since both terms of the ratio are again equally affected by such loss.

These characteristics contribute to the sensitivity and reproducibility of the procedure.

In order to validate and obtain data for the interpretation of the test, the technique has been applied in clinical situations where iron status could reasonably be inferred from other data.

HIGH IRON STORAGE STATES In all the clinical states tested in which iron stores were expected to be higher than normal, chelation in vivo as measured by this test gave results above the range for normal subjects. To this extent the method described distinguished between normal and high iron stores. However, the relationship of chelation to iron status is evidently a complex one. Appraisal of the amount of chelation in vivo $\left(\mathrm{F}_{\mathrm{v}}\right)$ in the cases tested shows that there is no simple proportion between stores and chelation in different haematological disorders. For instance, in the cases of pernicious anaemia the calculated increment in iron stores as ferritin and haemosiderin were of the order 1.0 to $1.5 \mathrm{~g}$. Fe, whereas in the haemochromatoses, iron stores 
would certainly be of the order of 20 to $40 \mathrm{~g}$. Fe. Nevertheless both conditions may yield chelation values in similar ranges. The amount of chelate formed therefore does not depend solely on the amount of storage iron as ferritin and haemosiderin. The two types of disorder giving markedly high $F_{v}$ values have nevertheless been differentiated in the test by the pattern of excretion, high $F_{d}$ values being characteristic of iron storage disease and low $F_{e x}$ values being characteristic of the haemolytic anaemias.

The dynamics of metal chelation have been shown to follow mass action laws (Schubert, 1961). If there were a proportional relationship between iron stores and chelation values, this would be evidence in favour of a single source of chelatable iron in a constant physico-chemical state. The $F_{\mathbf{v}}$ values obtained show that such conditions do not obtain in the various disorders of iron metabolism. There is in pernicious anaemia and other haemolytic states a source of chelatable iron far more reactive than ferritin and haemosiderin. It is known that newly deposited ferritin is more easily mobilized than old stores, and this may account for some of the difference in reactivity found in haemolytic conditions. But the observations in pernicious anaemia after vitamin $B_{12}$ therapy and in polycythemia vera after $\mathbf{P}^{32}$ therapy suggests that this is not a major factor in the chelation activities observed.

When polycythemia vera is treated with $\mathbf{P}^{32}$, haemoglobin falls and iron is transferred from haem to iron storage as ferritin and haemosiderin. This transfer is achieved not by increased breakdown of haemoglobin but by a decrease in the rate of haemoglobin formation. In the two cases studied decreases of haemoglobin of $4.2 \mathrm{~g} . \%$ and $8.4 \mathrm{~g} . \%$ coincided with increments in chelatable iron of 210 and $330 \mu \mathrm{g} . / \mathrm{kg}$. ferrioxamine respectively, clearly the result of newly deposited ferritin and haemosiderin.

In contrast, in three cases of pernicious anaemia during vitamin $\mathbf{B}_{12}$ therapy, chelatable iron decrements of 400,700 , and $250 \mu \mathrm{g}$. $/ \mathrm{kg}$. ferrioxamine were observed for comparatively minor increases in haemoglobin of $1.5 \mathrm{~g} . \%, 0.6 \mathrm{~g} . \%$, and $1.2 \mathrm{~g} . \%$ respectively.

The source of highly chelatable iron in pernicious anaemia does not therefore appear to be newly deposited ferritin. A significant feature of the effect of vitamin $B_{12}$ therapy on the amount of chelatable iron in pernicious anaemia is that the major change takes place before marked changes in haemoglobin. The earliest known effect of vitamin $B_{12}$ therapy is the cessation of intramedullary destruction of newly formed erythrons, referred to by Pollycove (1958) as 'ineffective erythropoiesis'. It may therefore be that a major site of chelation in pernicious anaemia and haemolytic states is iron newly released from hae in a reactive chelatable form.

It is postulated therefore that there are at leas two major sites of desferrioxamine chelation? namely, ferritin-haemosiderin stores and iron, which has just emerged from the haem molecule in chemically unidentified state.

IRON DEFICIENCY The cases of iron deficien reported here were unequivocally of iron-deficiency anaemia with haemoglobin less than $10 \mathrm{~g} . \%$, all of which later responded to iron therapy. In 26 of 360 patients, $F_{v}$ values were below the normal rang\& indicating low chelatable body iron. In five patients $F_{v}$ values appeared within the normal range. It $\dot{\bar{\delta}}$ evident that 'normals' and iron-deficient subjects must form a continuous series and therefore som overlap in $F_{v}$ values is to be expected: this will later assist in defining the lower limit of normal. Nevertheless, it seems that in at least four of these cases there was an unexpected source of mobilizeable iron.

Theoretically there are several possible sources storage iron may not be depleted even in the presence of severe iron-deficiency anaemia; on the basis $\overrightarrow{06}$ ferrikinetic studies, Pollycove (1958) maintains thå ineffective erythropoiesis is often a feature of irom deficiency, and if this were so it might provide source of chelatable iron as it appears to do pernicious anaemia; there may be an additional underlying pathology; it is not always possible to boํㅡㄹ certain beyond doubt that a patient has received no oral iron shortly before a test. These alternatis hypotheses are still under investigation.

SIGNIFICANCE OF VARIABLE CHELATION AVIDITY striking feature of iron metabolism is the way which sources and compartments of body iron are brought into the metabolic cycle in response varying conditions. For instance, iron released fro haemoglobin or iron absorbed from the intestine flows into the metabolic stream and is preferentialy utilized in the formation of new haem, while storage iron remains a relatively quiet backwater. TKe demonstration of sources of body iron with differing chelation susceptibility may allow of some insigh into how this is achieved.

It is possible, for instance, that differences chelatability with desferrioxamine may mean similar differences with physiological chelators such âs transferrin. In this way, iron derived from the constant breakdown of haemoglobin, in a form fạp more easily chelatable than storage iron, is prefer entially taken up by transferrin and fed back to the sites of haem synthesis. The evidence presented hege does not permil such a theory to be taken beyon this example. However, the hypothesis may 
offered of a system of ferrikinetics based on chelation gradients between chelators with varying avidity for iron and forms of iron with varying susceptibility to chelation.

I would like to thank Mrs. G. M. Brunström for her careful technical help; Professor P. L. Mollison for laboratory facilities during the early part of the investigation; my clinical colleagues for their cooperation; Ciba Ltd. for gifts of reagents and apparatus; and the North West Metropolitan Regional Hospital Board for a research grant.

\section{APPENDIX}

CALCULATION OF Fex, Fd, AND Fv

Dose of ferrioxamine injected

$$
=\frac{F}{\text { weight }}=0.833 \mathrm{mg} . / \mathrm{kg} .=833 \mu \mathrm{g} . / \mathrm{kg} \text {. }
$$

Concentration of ferrioxamine in injection solution

$$
=8.33 \mathrm{mg} . / \mathrm{ml} \text {. }
$$

If $\mathrm{V}_{\mathbf{s}}=$ volume of injected solution (ml.)

$\mathrm{C}_{\mathrm{s}}=\mathrm{Fe}^{59}$ activity of injected solution (c.p.m./ml.)

$\mathrm{V}_{\mathbf{u}}=$ volume of six-hour urine (ml.)

$\mathrm{C}_{\mathrm{u}}=\mathrm{Fe}^{59}$ activity of urine (c.p.m./ml.)

Then ferrioxamine injected $=V_{s} \times 8.33 \mathrm{mg}$. total counts injected $=V_{s} \times C_{s}$.

counts excreted in six hours $=\mathrm{V}_{\mathrm{u}} \times \mathrm{C}_{\mathrm{u}}$.

$$
\begin{aligned}
F_{\mathrm{ex}} & =\frac{\mathrm{V}_{\mathrm{u}} \times \mathrm{C}_{\mathrm{u}}}{\mathrm{V}_{\mathrm{s}} \times \mathrm{C}_{\mathrm{s}}} \times \mathrm{V}_{\mathrm{s}} \times 8.33 \mathrm{mg} . \\
& =\frac{\mathrm{V}_{\mathrm{u}} \times \mathrm{C}_{\mathrm{u}} \times 8.33 \mathrm{mg} .}{\mathrm{C}_{\mathrm{s}}}
\end{aligned}
$$

$$
\begin{aligned}
& F_{d}=F_{t}-F_{e x} m g . \\
& F_{v}=\frac{F_{d}}{F_{e x}} \times \frac{F}{\text { weight }}=\frac{F_{d}}{F_{e x}} \times 833 \mu \mathrm{g} . / \mathrm{kg} .
\end{aligned}
$$

\section{REFERENCES}

Bannerman, R. M., Callender, S. T., and Williams, D. L. (1962). Brit. med. J., 2, 1573.

Beutler, E., Fairbanks, V. F., and Fahey, J. L. (1963). Clinical Disorders of Iron Metabolism. Grune and Stratton, New York. Fielding, J. (1964). Unpublished observations.

- and Brunström, Gillian M. (1964). J. clin. Path., 17, 394.

Finch, C. A. (1959). J. clin. Invest., 38, 392.

Hallberg, L. (1964). In Iron Metabolism, p. 592. Springer, Berlin.

Harris, J. W. (1963). The Red Cell, p. 31. Harvard University Press, Cambridge, Mass.

Haskins, D., Stevens, A. R. Jr., Finch, S., and Finch, C. A. (1952). J. clin. Invest., 31, 543.

Heilmeyer, L., Keller, W., Vivell, O., Keiderling, W., Betke, K. Wöhler, F., and Schultze, H. E. (1961). Dtsch. med. Wschr., 86, 1745.

Hynes, M. (1949). J. clin. Path., 2, 99.

Keberle, H. (1964). Ciba information.

Korman, S. (1960). Ann. N.Y. Acad. Sci., 88, 460.

Mann, M., and Meier, C (1962). Schweitz. med. Wschr., 92, 1295.

Moeschlin, S. (1962). In Discussion, Ibid., 92, 1295.

Morgan, E. H., and Waters, M. N. I. (1963). J. clin. Path., 16, 101.

Peters, G. (1964). In Iron Metabolism, p. 518. Springer, Berlin.

Pollycove, M. (1958). In Iron in Clinical Medicine, edited by R. O. Wallerstein and S. R. Mettier, p. 43. University of California Press, Berkeley.

Rath, C. E., and Finch, C. A. (1948). J. Lab. clin. Med., 33, 81.

Schubert, J. (1961). Fed. Proc., 20, suppl., no. 10, 219.

- (1964). In Iron Metabolism, p. 466. Springer, Berlin.

Shoden, A., and Sturgeon, P. (1960). Acta haematol. (Basel), 23, 376.

Ventura, S. (1964). In Iron metabolism, p. 597. Springer, Berlin.

Williams, R., Scheuer, P. J., and Sherlock, S. (1962). Quart.J. Med., 31, 249.

Wöhler, F. (1962). In Discussion, Schweitz. med. Wschr., 92, 1295. 